\title{
Plasma levels of total, free and protein bound thiols as well as sulfane sulfur in different age groups of rats
}

\author{
Małgorzata Iciek ${ }^{1}$, Grażyna Chwatko ${ }^{2}$, Elżbieta Lorenc-Koci ${ }^{3}$, Edward Bald $^{2}$ and \\ Lidia Włodek ${ }^{1 \bowtie}$
}

${ }^{1}$ Institute of Medical Biochemistry, Collegium Medicum, Jagiellonian University; Kraków, Poland; ${ }^{2}$ Department of Environmental Chemistry, University of Eódż, Eódż, Poland;

${ }^{3}$ Department of Neuropsychopharmacology, Institute of Pharmacology, Polish Academy of Sciences, Kraków, Poland

Received: 19 November, 2003; revised: 01 April, 2004; accepted: 17 May, 2004

Key words: plasma, age, thiols, disulfides, sulfane sulfur

\begin{abstract}
The redox status of plasma thiols can be a diagnostic indicator of different pathological states. The aim of this study was to identify the age dependent changes in the plasma levels of total, free and protein bound glutathione, cysteine and homocysteine. The determination was conducted in plasma of three groups of rats: 1) young (3-month-old), 2) middle aged (19-month-old), and 3) old (31-month-old). Total levels of glutathione, cysteine and homocysteine and their respective free and protein-bound fractions decreased with age. The only exception was a rise in free homocysteine concentration in the middle group, which indicates a different pattern of transformations of this thiol in plasma. The drop in the level of protein-bound thiols suggests that the antioxidant capacity of plasma diminishes with age, which, consequently, leads to impaired protection of -SH groups through irreversible oxidation. The plasma sulfane sulfur level also declines with age, which means that aging is accompanied by inhibition of anaerobic sulfur metabolism.
\end{abstract}

Thiol compounds, such as glutathione (GSH), cysteine (CSH) and homocysteine (HCSH) are a natural reservoir of the reductive capacity of the cell. The most signif- icant of the multifarious roles played by thiols in vivo is their function as components of the intracellular and extracellular redox buffer. A diminished cellular GSH level accompanies

\footnotetext{
${ }^{\circledR}$ Corresponding author: Lidia Włodek, Institute of Medical Biochemistry, Collegium Medicum, Jagiellonian University, Kopernika 7, 31-034 Kraków, Poland; tel.: (48 12) 422 7400; fax: (48 12) 422 3272; e-mail: mbwlodek@cyf-kr.edu.pl

Abbreviations: CMOT, 2-chloro-1-methylquinolinium tetrafluoroborate; $\mathrm{CSH}$, cysteine; GSH, glutathione; GSSG, glutathione disulfide; GGT, $\gamma$-glutamyltransferase; HCSH, homocysteine; HCSSCH, homocysteine.
} 
such pathological states as diabetes, alcoholism, AIDS, acute hemorrhagic gastric erosions, cataract, neurological diseases, malnutrition and has also been observed during aging (Lang et al., 1992; Vogt \& Richie, 1993; Sian et al., 1994; Pirmohamed et al., 1996; Samiec et al., 1998; Hadi Yasa et al., 1999; Choi et al., 2000).

The concept of plasma redox status postulates that there are dynamic interactions between the different redox forms of thiols realized through redox reactions, including thiol-disulfide exchange (Ueland, 1995; Ueland et al., 1996). Formation and breakage of disulfide bonds depends largely on the vailability of electron donors and acceptors, which determines the redox potential of the environment. Therefore, a change in the thiol: disulfide ratio, i.e. a change in the redox status of thiols, significantly influences the structure and function of cellular and extracellular proteins (Mansoor et al., 1992).

Glutathione, cysteine and homocysteine are present in plasma mostly in the form of symmetrical and mixed disulfides, which belong to the free fraction, called acid-soluble fraction, and also to the protein-bound fraction. Since the plasma GSH concentration reflects its levels in various tissues, it is believed that a lowered plasma GSH level can be a diagnostic indicator of a pathological state. For this reason, and also due to the atherosclerotic action of homocysteine (McCully, 1996), thiols have become a focus of increasing interest.

Sulfur of cysteine - $\mathrm{SH}$ groups undergoes anaerobic transformations yielding compounds belonging to the pool of sulfane sulfur-containing compounds (Toohey, 1989; Iciek \& Włodek, 2001) (Scheme 1). Sulfane sulfur is characterized by exceptional metabolic reactivity, it is always at the 0 or -1 oxidation state, and is covalently bound to another sulfur atom. Sulfane sulfur allows for covalent modification of - $\mathrm{SH}$ groups to persulfides and trisulfides, which indicates a possibility of non-oxidizing covalent modification of -SH groups. Sulfane sulfur is transported in plasma in the form of hydropersulfides bound to proteins, mostly to albumins (Toohey, 1989). This means that sulfane sulfur is transported with blood from the liver and kidneys to other organs.

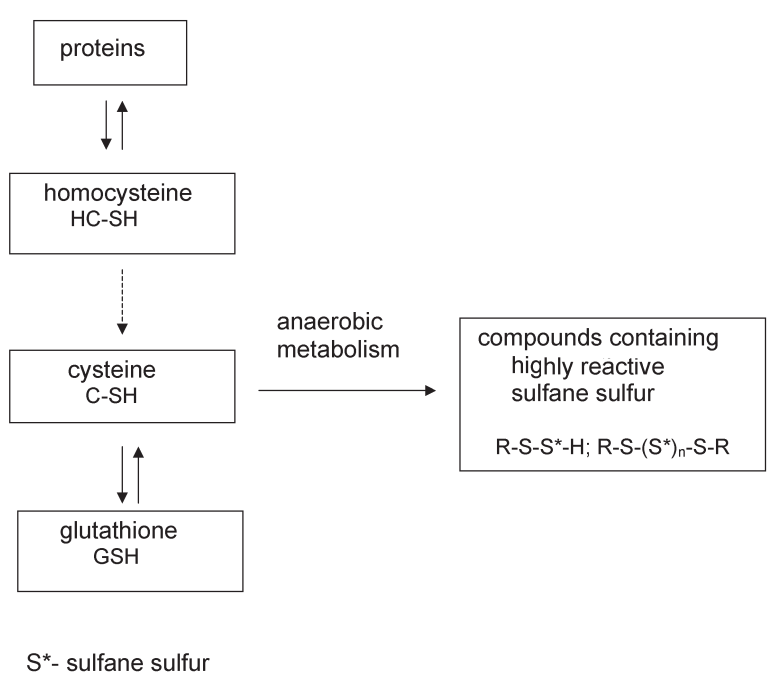

Scheme 1. Transformation of thiols to sulfane sulfur containing compounds.

The aim of the present study was to identify age-dependent changes in the plasma levels of individual thiols and their mutual relationships. For this purpose we determined plasma total levels of glutathione, cysteine and homocysteine, their respective free forms and their mixed disulfides with proteins in different age groups of rats. In addition, plasma sulfane sulfur levels were also measured.

\section{MATERIALS AND METHODS}

Chemicals. 2-Chloro-1-methylquinolinium tetrafluoroborate (CMQT) and 2,2'-dithiodipropionic acid were prepared in this laboratory according to Bald \& Głowacki (2001) and Chwatko \& Bald (2002). Cystine (CSSC) and oxidized glutathione (GSSG) were obtained from Reanal (Budapest, Hungary), while homocystine (HCSSCH) was from Serva (Heidelberg, Germany). All other chemicals of an- 
alytical reagent grade or HPLC grade were purchased from Merck (Darmstadt, Germany) or J. T. Baker (Deventer, The Netherlands). Deionized water was prepared using Millipore Milli-QRG (Vienna, Austria). Potassium cyanide (KCN) was obtained from Sigma-Aldrich Chemie GmbH (Germany) and other chemicals used for sulfane sulfur determination were purchased from the Polish Chemical Reagent Company P.O.Ch.

Animals. Plasma of female Wistar rats was obtained from the Department of Clinical Neurobiology, Free University in Berlin. All the rats were sacrificed by cervical dislocation. Blood samples were from the following three age groups: young (3-month-old), middle-aged (19-month-old) and old (31-monthold). Each group consisted of eight animals. All blood samples were centrifuged at $2500 \times$ g for 10 min to separate the plasma from cells and then stored at $-75^{\circ} \mathrm{C}$ until analysis.

Assays. Levels of total thiols as well as their free and protein-bound fractions were measured by high performance liquid chromatography (HPLC) after precolumn derivatization with 2-chloro-1-methylquinolinium tetrafluoroborate (CMQT) and with ultraviolet detection (CMQT-HPLC-UV method) (Bald \& Głowacki, 2001). The analysis was performed with a Hewlett-Packard 1100 Series HPLC system (Hewlett-Packard, Waldbronn, Germany) equipped with a quaternary pump, autosampler, thermostated column compartment, vacuum degasser and diode-array detector. For instrument control, data acquisition and data analysis, an HP ChemStation for LC 3D system including single instrument HP ChemStation software and Vectra colour computer were used.

The CMQT-HPLC-UV method provides quantitative information on total, free and protein-bound thiols based on assays with derivatization after reduction of whole plasma or its acid-soluble and acid-precipitated fractions, respectively. Samples were reduced with sodium borohydride. Such procedure of reduction is used in automatic thiol assay systems. HPLC separations, after automatic injection of $20 \mu \mathrm{l}$ of the final analytical solution, were carried out with an analytical reversed-phase column LichroCart $(125 \times 3$ $\mathrm{mm})$ packed with $5 \mu \mathrm{m}$ particles of Lichrospher RP Select B (Merck). The temperature was $25^{\circ} \mathrm{C}$, the flow rate $0.8 \mathrm{ml} / \mathrm{min}$, and the detector wavelength $350 \mathrm{~nm}$. Under gradient elution conditions CMQT derivatives of GSH, HCSH, 2MPA and CSH were eluted after 3.53, 3.84, 4.45, $9.37 \mathrm{~min}$, respectively. The gradient profile was as follows: $0-3.5$ min, 9\% B; 3.5-10 min, $9-30 \%$ B; $10-13 \mathrm{~min}$, $30-9 \%$ B. Elution solvent A was $0.05 \mathrm{M}$ trichloroacetic acid adjusted to $\mathrm{pH} 3.2$ with lithium hydroxide solution of the same concentration. Solvent B was acetonitrile. Identification of peaks was based on comparison of retention times and diode-array spectra with the corresponding set of data obtained by analyzing authentic compounds. In order to minimize the contribution of sample preparation, injection variation and column deterioration to the final results, an internal standard - 2,2'-dithiodipropionic acid was used. Disulfide forms of corresponding analytes, i.e., cystine, oxidized glutathione, and homocystine were used as the main calibrators during the calibration procedure. Details of the HPLC measurements have been described elsewhere (Chwatko \& Bald, 2002).

The level of sulfane sulfur in plasma was determined by cold cyanolysis according to Wood (1987). To $0.4 \mathrm{ml}$ of plasma $0.08 \mathrm{ml}$ of 1 $\mathrm{M} \mathrm{NH}_{3}, 0.42 \mathrm{ml}$ of distilled water and $0.1 \mathrm{ml}$ of $0.5 \mathrm{M} \mathrm{KCN}$ were added. The samples were incubated at room temperature for $45 \mathrm{~min}$. Then $0.02 \mathrm{ml}$ of $38 \%$ formaldehyde and $0.2 \mathrm{ml}$ of Goldstein's reagent $\left(\mathrm{Fe}\left(\mathrm{NO}_{3}\right)+\mathrm{HNO}_{3}+\right.$ $\mathrm{H}_{2} \mathrm{O}$ ) were added. After centrifugation at $12000 \times \boldsymbol{g}$ for $10 \mathrm{~min}$, the absorbance at 460 $\mathrm{nm}$ was determined. A standard curve was prepared with $1 \mathrm{mM}$ KSCN.

Statistical analysis. The results were presented as means \pm standard deviation ( \pm S.D.). Statistical significance of the differences was evaluated using analysis of variance and one 


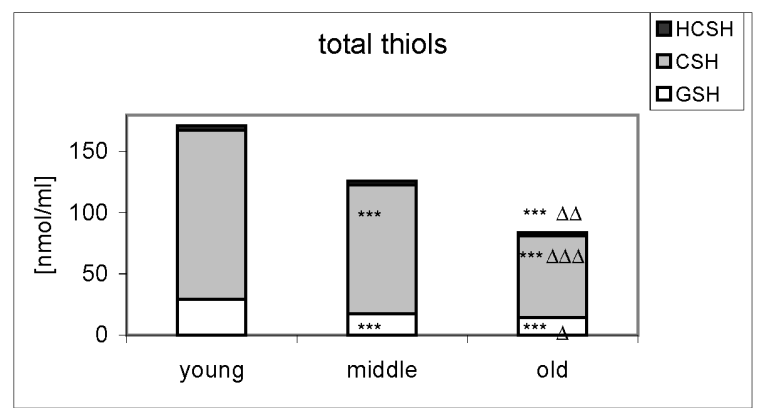

Figure 1. Total plasma levels of thiols (glutathione, cysteine and homocysteine) in young (3 months old), middle (19 months old) and old (31 months old) rats.

${ }^{* * *} P<0.001$ significantly different from the first group (young); ${ }^{\Delta} P<0.05,{ }^{\Delta \Delta} P<0,01,{ }^{\Delta \Delta \Delta} P<0.001$ significantly different from the second group (middle age).

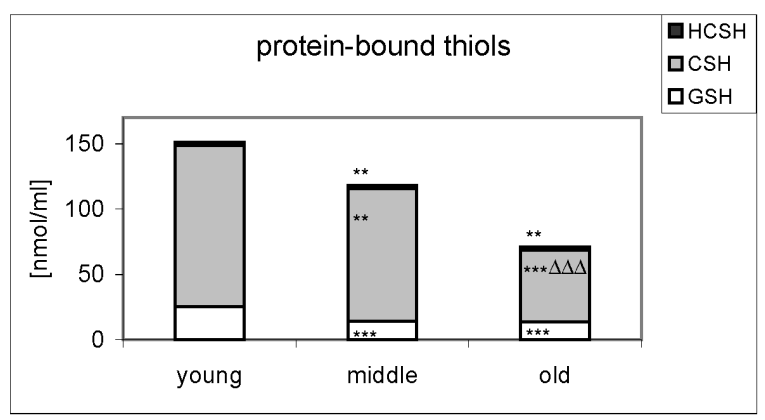

Figure 2. Plasma protein-bound thiols (glutathione, cysteine and homocysteine) in young ( 3 months old), middle (19 months old) and old (31 months old) rats.

${ }^{* *} P<0.01,{ }^{* * *} P<0.001$ significantly different from the first group (young); ${ }^{\Delta \Delta \Delta} P<0.001$ significantly different from the second group (middle age).

way ANOVA test. The difference was considered statistically significant when $P<0.05$.

\section{RESULTS}

The levels of free and protein-bound thiols as well as sulfane sulfur level were determined in three age groups of rats (young -3 months old; middle - 19 months old; and old - 31 months old). The results illustrated in

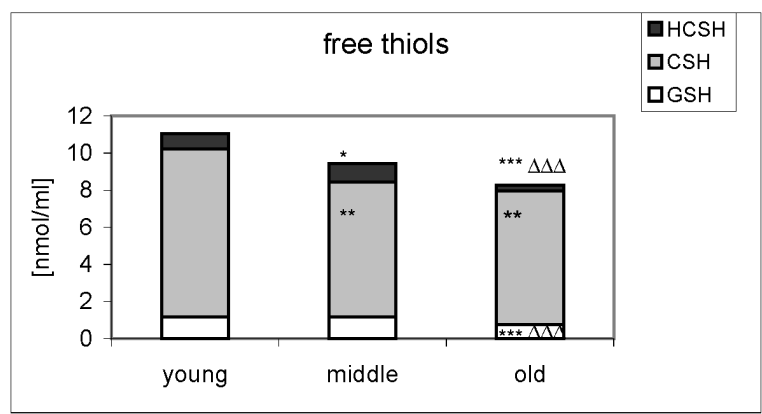

Figure 3. Free thiols in plasma (glutathione, cysteine and homocysteine) in young ( 3 months old), middle (19 months old) and old (31 months old) rats.

${ }^{*} P<0.05,{ }^{* *} P<0.01,{ }^{* * *} P<0.001$ significantly different from the first group (young); ${ }^{\Delta \Delta} P<0.05$, ${ }^{\Delta \Delta \Delta} P<0.001$ significantly different from the second group (middle age).

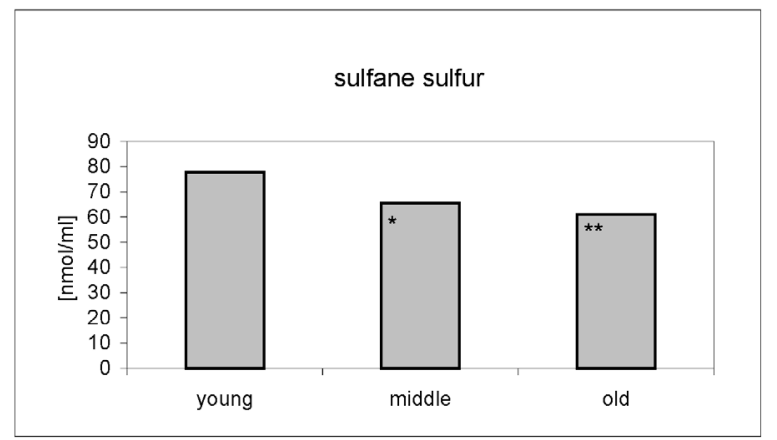

Figura 4. Plasma level of sulfane sulfur compounds in young ( 3 months old), middle (19 months old) and old (31 months old) rats.

${ }^{*} P<0.05,{ }^{* *} P<0.01$ significantly different from the first group (young).

Figs. 1-4 show age-dependent lowering of plasma concentrations of all forms of thiols as well as sulfane sulfur.

Total thiols (i.e., the sum of cysteine, homocysteine and glutathione) declined with age from 171.32 to $83.87 \mathrm{nmol} / \mathrm{ml}$ of plasma (Fig. 1). They decreased uniformly by about $30 \%$ between the consecutive age group. The pattern of the age-dependent changes in protein-bound thiols was similar (Fig. 2). The level of each tested thiol (i.e. cysteine, homocysteine and glutathione) bound to proteins, and their total concentration abated with age 
(the latter decreased to $78 \%$ in the middle group and to $47 \%$ in old animals in relation to the young group).

Cysteine constitutes $80 \%$, glutathione $17 \%$ and homocysteine $2-3 \%$ of the total tiol group, respectively. This ratio remains the same in all age groups. The changes involve only the free/protein-bound thiol rates. in plasma. This ratio for homocysteine was particularly high in the middle group (42.13) compared to the young (29.09) and old rats (13.90).

The pool of sulfane sulfur also subsided with age but to a lesser degree than that of total thiols (Fig. 4). The plasma level of the compounds containing this extremely reactive

Table 1. Free/protein-bound thiol ratios in the young, middle and old groups of rats

\begin{tabular}{llll}
\hline thiols & \multicolumn{3}{c}{$\begin{array}{c}\text { free/protein-bound } \\
(\times 100)\end{array}$} \\
\hline & glutathione & cysteine & homocysteine \\
young & 4.60 & 7.36 & 29.09 \\
middle & 8.08 & 7.20 & 42.13 \\
old & 5.59 & 13.15 & 13.90 \\
\hline
\end{tabular}

The total concentration of free thiols also declined with age (Fig. 3) but the change was much less pronounced than for protein-bound thiols. The level of free glutathione was the same in the young and middle groups of rats, decreasing only in the oldest group (67\%). On the other hand, plasma concentration of free cysteine decreased with age ( $80 \%)$ but the difference between middle and the oldest group was minute, while free homocysteine was an exception, since its highest level was observed in the middle group $(121 \%$ of that in young animals) decreasing in the oldest one (37\%) (Fig. 3).

The changes observed in the plasma levels of thiols in the different age groups were accompanied by alterations in free/proteinbound thiol ratios (Table 1). This ratio for glutathione was the lowest in the young group (4.60), reaching maximum in the middle one (8.08). The situation was different in the case of cysteine, whose free / protein-bound ratios were similar in the young (7.36) and middle groups (7.20), and rose sharply in the old one (13.15). The homocysteine free/proteinbound ratio was high in comparison with those of cysteine and glutathione, which points to a significant role of this amino acid form of sulfur dropped with age to $84 \%$ in the middle and to $78 \%$ in the old group in comparison with the young group.

\section{DISCUSSION}

According to the "free radical" theory of Harman (1981), the aging process is a progressive accumulation of oxidative changes leading to disease and death. With age, plasma also becomes more exposed to increasing attack of reactive oxygen species (ROS), generated by activated phagocytes, and formed in reactions of different metabolites with oxygen.

Aging is accompanied by a decrease in the level of the most important antioxidant glutathione and of cysteine (Samiec et al., 1998), which can be a result of both an elevated demand and inhibited GSH biosynthesis. Thiol groups $(-\mathrm{SH})$ play a prominent role in antioxidant reactions, and also in reactions of catalysis, regulation, electron transport and those preserving the correct structure of proteins (Rokutan et al., 1994).

The levels and mutual relations between different redox forms of thiols in plasma are de- 
cisive for the plasma redox capacity, which determines its proper function. For all these reasons, plasma thiols (CSH, GSH, HCSH) should be considered not only as metabolites transported between organs and tissues, but also as functionally important plasma components. Most studies dealt with free thiols, while much less attention has been paid to the significance and quantification of protein-bound thiols in plasma. Mixed disulfides with proteins are formed by reaction of S-thiolation, in which protein thiols conjugate with non-protein thiols (Mills \& Lang, 1996; Klatt \& Lamas, 2000; Thomas \& Mallis, 2000). This process plays a regulatory and an antioxidant role, since it protects protein - $\mathrm{SH}$ groups against irreversible oxidation to $-\mathrm{SO}_{2} \mathrm{H}$ and $-\mathrm{SO}_{3} \mathrm{H}$, and, on the other hand, it participates in signal transduction (Padget \& Whorton, 1998; Klatt \& Lamas, 2000). The regulatory and antioxidant action of S-thiolation is closely connected with dethiolation, i.e. the reduction of disulfides catalyzed by thioltransferases, thioredoxin and glutaredoxin (Jung \& Thomas, 1996; Qiao et al., 2000). Generation of mixed disulfides of proteins which do not have another - $\mathrm{SH}$ group in their vicinity is particularly important. It was shown that formation of mixed disulfides of proteins could constitute a protective mechanism in lens (Lou, 2000), vascular endothelium cells (Schuppe-Koistinen et al., 1994) and gastric mucosa (Rokutan et al., 1994). Formation of mixed disulfides can stimulate or inhibit the activity of many enzymes, such as aldose reductase, cathepsin $\mathrm{K}$ and carbonic anhydrase III (Dafre et al., 1996; Percival et al., 1999; Cappiello et al., 2000; Mallis et al., 2002).

The present study demonstrated an age-dependent reduction in the total amount of glutathione, cysteine and homocysteine, and their free and protein-bound fractions in rat plasma (Figs. 1-3). This indicates that the efficiency of S-thiolation as a mechanism of antioxidant defense decreases with age, which creates an increased risk of irreversible oxi- dation of -SH groups of plasma proteins. The drop in the plasma level of mixed disulfides implies depletion of the antioxidant capacity of plasma, and thus disturbance of the balance between the different redox forms of thiols. All changes in the redox status of thiols in plasma and cytoplasm significantly affect the structure and function of proteins among them membrane proteins. The results obtained in the present study indicate that protection of - $\mathrm{SH}$ groups by S-thiolation becomes less and less efficient with age and concerns not only $S$-glutathionylation, but also S-cysteinylation and S-homocysteinylation (Figs. 1-3).

The plasma concentration of individual thiols is determined by their "influx" and "efflux" (Kleinman \& Richie, 2000), so it depends both on the biosynthesis and the increased demand. Plasma GSH is synthesized in liver, while its degradation in the kidney brush border epithelium is catalyzed by the extracellular enzymes $\gamma$-glutamyltransferase (GGT) and cysteinyl-glycine dipeptidase (Anderson et al., 1980). This suggests that kidneys are responsible for maintaining normal plasma cysteine level. Since the activity of GGT in the kidney drops with age (Włodek et al., 2002), the inter-organ transport and biodegradation of GSH are impaired, which leads to lowering of the plasma cysteine level. The drop in plasma cysteine is particularly dangerous for the organs which rely on plasma as the only source of this amino acid. On the other hand, Speisky (1992) showed that liver GGT activity in old animals is higher than in middle-aged ones. This implies that GSH cleavage to cysteine in the liver increases with age.

Sulfane sulfur compounds not only participate in the regulation of protein activity (Iciek \& Włodek, 2001), but also exhibit antioxidant potential (Everett et al., 1994). Hydropersulfides (RSSH) are more efficient hydrogen donors while persulfide anions $\left(\mathrm{RSS}^{-}\right)$are better electron donors than the sulfhydryl group (-SH), which makes them 
very effective antioxidants. Moreover, perthiyl radicals ( $\mathrm{RSS}^{\circ}$ ) formed in the course of these reactions are characterized by higher stability, so they are less dangerous than thiyl radicals ( $\mathrm{RS}^{\bullet}$ ) (Everett et al., 1994).

Plasma sulfane sulfur level also declines with age (Fig. 4), which means that aging is accompanied by disturbances in the regulatory and antioxidant mechanisms connected with sulfane sulfur in plasma.

The total plasma level of homocysteine and the content of its mixed disulfides with proteins decrease with age, while the level of free homocysteine significantly increases in middle-aged animals (Fig. 3). Homocysteine is characterized also by a high free/proteinbound thiol ratio, which indicates that free homocysteine constitutes a large fraction of its total pool (Table 1). Hyperhomocysteinemia and associated atherosclerosis play a significant role in diseases of old age. There are discrepant data about age-dependent changes in plasma homocysteine level. Some authors observed its increase (Hernanz et al., 2000), but this was not confirmed by others (Rea et al., 2000). The atherogenic action of homocysteine has been attributed to its autooxidation connected with the formation of $\mathrm{O}_{2}^{-\bullet}$ and $\mathrm{H}_{2} \mathrm{O}_{2}$, which causes dysfunction of endothelium and promotes atherosclerosis (Welch et al., 1997). However, spontaneous oxidation of homocysteine to a disulfide, homocystine, is slow and only slightly faster than oxidation of GSH. The reactivity of thiols in S-thiolation reactions depends on $\mathrm{p} K$ of the thiol groups, i.e. on the degree of dissociation of the -SH group to the nucleofilic thiolate anion $\left(-\mathrm{S}^{-}\right)$. The $\mathrm{p} K_{\mathrm{a}}$ values for cysteine, homocysteine and GSH are 8.3, 8.87, and 9.2 respectively (Lash \& Jones, 1985). On the basis of $\mathrm{p} K_{\mathrm{a}}$ of an -SH group, it is possible to calculate the ratio of the dissociated thiolate $\left(\mathrm{RS}^{-}\right)$to undissociated thiol, using the equation:

$$
\mathrm{RS}^{-} / \mathrm{RSH}=10^{\left(\mathrm{pH}-\mathrm{p} K_{\mathrm{a}}\right)}
$$

These ratios for the physiological $\mathrm{pH} 7.4$ are: $\mathrm{CS}^{-} / \mathrm{CSH}=10^{(7.4-8.3)}=0.126$ for cysteine, $\mathrm{GS}^{-} / \mathrm{GSH}=10^{(7.4-9.2)}=0.016$ for glutathione, and $\mathrm{HCS}^{-} / \mathrm{HCSH}=10^{(7.4-8.87)}=$ 0.034 for homocysteine (Lash \& Jones, 1985). Cysteine thiolate anion is much more thermodynamically stable than homocysteine thiolate anion, because the $\mathrm{p} K_{\mathrm{a}}$ of homocysteine is higher than that of cysteine. Thus the formation of albumin-bound homocysteine is preferred to the formation of albumin-bound cysteine (Sengupta et al., 2001). This indicates that in plasma, reduced homocysteine can reduce protein-bound cysteine and disulfide-cystine to reduced cysteine.

$$
\begin{gathered}
\text { HC-SH + Alb-S-S-C } \longrightarrow \\
\text { Alb-S-S-C-H + C-SH } \\
\text { 2HC-SH + C-S-S-C } \longrightarrow \\
2 \mathrm{C}-\mathrm{SH}+\mathrm{HC}-\mathrm{S}-\mathrm{S}-\mathrm{C}-\mathrm{H}
\end{gathered}
$$

This in turn can lead to autooxidation of liberated cysteine and generation of reactive oxygen species (ROS) promoted by this amino acid, which is conducive to atherosclerosis (Hogg, 1999). In this respect, cysteine can be regarded as toxic (Włodek, 2002).

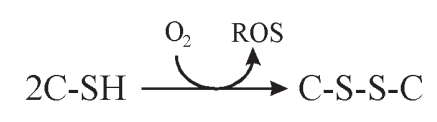

An increase in the cysteine/cystine ratio from 0.01 to almost 0.5 , observed in patients with hyperhomocysteinemia (Hogg, 1999), is consistent with the above mechanism. The transient elevation of free homocysteine concentration in the middle group of rats (Fig. 3), but the lowest free/protein-bound ratio in the oldest group with the concomitant the highest value of this parameter for cysteine (Table 1) indicates opposite age-dependent changes in the redox status of both these thiols in plasma.

In summary, the total plasma levels of GSH, cysteine and homocysteine and of their re- 
spective free and protein-bound fractions decrease with age, which is accompanied by a drop in sulfane sulfur level. The only exception is a rise in free homocysteine concentration in the middle group, which indicates a different pattern of transformations of this thiol in plasma. The drop in the level of protein-bound thiols suggests that the antioxidant capacity of plasma diminishes with age, which consequently leads to impaired protection of protein - $\mathrm{SH}$ groups from irreversible oxidation. Aging is associated not only with a decrease in the concentration of different redox forms of thiols, but also with a change in their free/protein-bound ratios. The observation that the free/protein-bound ratio for homocysteine is the lowest, while for cysteine it is the highest in the oldest group, indicates that the age-dependent changes in the ratios of free to protein-bound plasma thiols can be opposite.

\section{R E F E R E N C E S}

Anderson ME, Bridges RJ, Meister A. (1980) Direct evidence for inter-organ transport of glutathione and that the non-filtration renal mechanism for glutathione utilization involves $\gamma$-glutamyl transpeptidase. Biochem Biophys Res Commun.; 96: 848-53.

Bald E, Głowacki R. (2001)

2-Chloro-1-methylquinolinium tetrafluoroborate as an effective and thiol specific UV-tagging reagent for liquid chromatography. J Liq Chromatogr Rel Technol.; 24: 1323-39.

Cappiello M, Vilardo PG, Micheli V, Jacomelli G, Banditelli S, Leverenz V, Giblin FJ, del Corso A, Mura U. (2000) Thiol disulfide exchange modulates the activity of aldose reductase in intact bovine lens as a response to oxidative stress. Exp Eye Res.; 70: 795-3.

Choi J, Liu RM, Kundu RK, Sangiorgi F, Wu W, Maxson R, Forman HJ. (2000) Molecular mechanism of decreased glutathione content in human immunodeficiency virus type 1
Tat-transgenic mice. $J$ Biol Chem.; 275: 3693-8.

Chwatko G, Bald E. (2002) Determination of different species of homocysteine in human plasma by high-performance liquid chromatography with ultraviolet detection. $J$ Chromatogr A.; 949: 141-51.

Dafre AL, Sies H, Akerboom T. (1996) Protein S-thiolation and regulation of microsomal glutathione redox couple. Arch Biochem Biophys.; 332: 288-94.

Everett SA, Folkes LK, Wardman P. (1994) Free radical repair by a novel perthiol: reversible hydrogen transfer and perthiyl radical formation. Free Radic Res.; 20: 387-400.

Hadi Yasa M, Kacmaz M, Serda Ozturk M, Durak J. (1999) Antioxidant status of erythrocyte from patients with cirrhosis. Hepato-Gastroenterology.; 46: 2460-3.

Harman D. (1981) The aging process. Proc Natl Acad Sci USA.; 78: 7124-8.

Hernanz A, Fernandez-Vivancos E, Salazar RM, Arnalich F. (2000) Homocysteine and other thiol compounds in ageing. Biofactors.; 11: 47-9.

Hogg N. (1999) The effect of cyst(e)ine on the auto-oxidation of homocysteine. Free Radic Biol Med.; 27: 28-33.

Iciek M, Włodek L. (2001) Biosynthesis and biological properties of compounds containing highly reactive reduced sulfane sulfur. $\mathrm{Pol} J$ Pharmacol.; 53: 215-25.

Jung CH, Thomas JA. (1996) S-glutathiolated hepatocyte proteins and insulin disulfides as substrates for reduction by glutaredoxin, thioredoxin, protein disulfide isomerase and glutathione. Arch Biochem Biophys.; 335: 61-72.

Klatt P, Lamas S. (2000) Regulation of protein function by S-glutathiolation in response to oxidative and nitrosative stress. Eur $J$ Biochem.; 267: 4928-44.

Kleinman WA, Richie JP Jr. (2000) Status of glutathione and other thiols and disulfides in human plasma. Biochem Pharmacol.; 60: 19-29. 
Lang CA, Naryshkin S, Schneider DL, Mills BJ, Lindeman RD. (1992) Low blood glutathione levels in healthy aging adults. $J$ Lab Clin Med.; 120: 720-5.

Lash LH, Jones DP. (1985) Distribution of oxidized and reduced forms of glutathione and cysteine in rat plasma. Arch Biochem Biophys.; 240: 583-92.

Lou MF. (2000) Thiol regulation in the lens. $J$ Ocul Pharmacol Ther; 16: 137-48.

Mallis RJ, Hamann MJ, Zhao W, Zhang T, Hendrich S, Thomas JA. (2002) Irreversible thiol oxidation in carbonic anhydrase III: protection by S-glutathiolation and detection in aging rats. Biol Chem.; 383: 649-62.

Mansoor MA, Svardal AM, Schneede J, Ueland PM. (1992) Dynamic relation between reduced, oxidzed and protein bound homocysteine and other thiol compounds in plasma during methionine loading in healthy men. Clin Chem.; 38: 1316-21.

McCully KS. (1996) Homocysteine and vascular disease. Nat Med.; 2: 386-9.

Mills BJ, Lang CA. (1996) Differential distribution of free and bound glutathione and cyst(e)ine in human blood. Biochem

Pharmacol.; 52: 401-6.

Padgett CM, Whorton AR. (1998) Cellular responses to nitric oxide: role of protein S-thiolation/dethiolation. Arch Biochem Biophys.; 358: 232-42.

Percival MD, Quellet M, Campagnolo C, Claveau D, Li C. (1999) Inhibition of cathepsin K by nitric oxide donors: evidence for the formation of mixed disulfides and a sulfenic acid. Biochemistry.; 38: 13574-83.

Pirmohamed M, Williams D, Tingle MD, Barry M, Khoo S, O’Mahony C, Wilkins EG, Breckenridge AM, Park BK. (1996) Intracellular glutathione in the peripheral blood cell of HIV-infected patients: failure to show a deficiency. AIDS.; 10: 501-7.

Qiao F, Xing K, Lou MF. (2000) Modulation of lens glycolytic pathway by thioltransferase. Exp Eye Res.; 70: 745-53.
Rea IM, McMaster D, Woodside JV, Young IS, Archbold GP, Linton T, Lennox S, McNulty H, Harmon DL, Whitehead AS. (2000) Community-living nonagenarians in Northern Ireland have lower plasma homocysteine but similar methylenetetrahydrofolate reductase thermolabile genotype prevalence compared to 70-89-year-old subjects. Atherosclerosis.; 149: $207-14$.

Rokutan K, Johnston RB Jr, Kawai K. (1994) Oxidative stress induces S-thiolation of specific proteins in cultured gastric mucosal cells. Am J Physiol.; 266: G247-54.

Samiec PS, Drews-Botsch C, Flagg EW, Kurtz JC, Sternberg P Jr, Reed RL, Jones DP. (1998) Glutathione in human plasma: decline in association with aging, age-related macular degeneration and diabetes. Free Radic Biol Med.; 24: 699-704.

Schuppe-Koistinen I, Moldeus P, Bergman T, Cotgreave IA. (1994) S-Thiolation of human endothelial cell glyceraldehyde-3-phosphate dehydrogenase after hydrogen treatment. Eur J Biochem.; 221: 1033-7.

Sengupta S, Chen H, Togawa T, DiBello PM, Majors AK, Budy B, Ketterer M, Jacobsen DW. (2001) Albumin thiolate anion is an intermediate in the formation of albumin-S-S-homocysteine. J Biol Chem.; 276: 30111-7.

Sian J, Dexter DT, Lees AJ, Daniel S, Agid Y, Javoy-Agid F, Jenner P, Marsden CD. (1994) Alteration of glutathione levels in Parkinson's disease and other neurodegenerative disorders affecting basal ganglia. Ann Neurol.; 36: 348-55.

Speisky H. (1992) Age-dependent removal of circulating glutathione by rat liver: role of gamma-glutamyl transferase. Age.; 15: 104-7.

Thomas JA, Mallis RJ. (2000) Aging and oxidation of reactive protein sulfhydryls. Exp Geront.; 36: 1519-26.

Toohey JI. (1989) Sulphane sulphur in biological systems: a possible regulatory role. Biochem J.; 264: 625-32. 
Ueland PM. (1995) Homocysteine species as components of plasma redox thiol status. Clin Chem.; 41: 340-2.

Ueland PM, Mansoor MA, Guttormsen AB, Muller F, Aukrust P, Refsum H, Svardal AM. (1996) Reduced, oxidized and protein-bound forms of homocysteine and other aminothiols in plasma comprise the redox thiol status a possible element of the extracellular antioxidant defense system. $J$ Nutr; 126: $1281 \mathrm{~S}-4 \mathrm{~S}$

Vogt BL, Richie JP Jr. (1993) Fasting-induced depletion of glutathione in the aging mouse. Biochem Pharmacol.; 46: 257-63.
Welch GN, Upchurch GR Jr, Loscalzo J. (1997) Homocysteine, oxidative stress and vascular disease. Hosp Pract.; 32: 81-92.

Włodek L. (2002) Causes of L-cysteine neurotoxicity. Acta Biol Cracoviensia.; 44: $15-24$.

Włodek P, Sokołowska M, Smoleński O, Włodek L. (2002) The $\gamma$-glutamyltransferase activity and non-protein sulfhydryl compounds levels in rat kidney of different groups. Acta Biochim Polon.; 49: 501-7.

Wood JL. (1987) Sulfane sulfur. Methods Enzymol.; 143: 25-9. 